\title{
Elevated Plus Maze and Y-Maze Behavioral Effects of Subchronic, Oral Low Dose Monosodium Glutamate in Swiss Albino Mice
}

\author{
Olakunle James ONAOLAPO ${ }^{1}$, Adejoke Yetunde ONAOLAPO ${ }^{2}$, Tolulope Josiah \\ MOSAKU $^{3}$, Onigbinde Oluwanisola Akanji ${ }^{4}$ and Oyedele Rotimi Abiodun ${ }^{5}$ \\ ${ }^{I}$ Department of Pharmacology, Faculty of Basic Medical Sciences, College of Health Sciences, Ladoke \\ Akintola University, Oshogbo, Osun State. \\ 2,3,4,5 Department of Human Anatomy, Faculty of Basic Medical Sciences, College of Health Sciences, Ladoke \\ Akintola University, Ogbomoso, Oyo State.
}

\begin{abstract}
Effects of subchronic oral low dose monosodium glutamate (MSG) on neurobehavior were assessed using the $Y$ and Elevated plus mazes in mice. Forty adult Swiss albino mice weighing between 20-25 g were assigned into four groups $A, B, C$ and $D$. Group $A$ served as control and received normal saline, groups $B$, $C$ and D received MSG dissolved in normal saline orally at $0.5,1.0$ and $1.5 \mathrm{mg} / \mathrm{kg}$ dose. MSG or vehicle was administered for a period of 14 days, following which animals were exposed to the elevated plus maze (EPM) and the Y-maze. The numbers of entries and percentage time spent in the open and closed arms after 5mins exposure to the plus maze and $Y$-maze spontaneous alternations over a five minute period was scored for each animal as a measure of spatial memory. Result were analysed by one way ANOVA followed by a posthoc test, results were expressed as mean \pm S.E.M. Elevated plus maze performance showed a significant decrease in the number of entries and time spent in the open arm and an increase in the total number of arm entries compared to control, Y-maze task performance showed no significant improvement in the MSG groups compared to control. The study concluded that subchronic MSG at the doses administered was anxiogenic but had only a slight retardant effect on spatial working memory.
\end{abstract}

Keywords: Neurobehavior, Monosodium glutamate, Anxiety, Spatial Memory, Brain Glutamate

\section{Introduction}

Glutamate exists in large quantities in nature and it forms the building block of many proteins. Glutamate is also present unbounded in many body organs and tissues and it can be found in milk, vegetables, seafood and poultry. It is also an important part of traditional seasonings like fish and soy sauce. About a decade ago the taste of glutamate as the fifth basic taste termed "umami" was discovered (1). German scientist Ritthausen isolated glutamate from acid hydrolysate of wheat in the form of glutamic acid in 1866. In the brain, glutamate is found in large quantities as it is synthesized at rates that are proportionate to the brain's metabolic demands (2). Fluctuations of plasma glutamate levels are usually seen from day to day following dietary intake, metabolism and protein turnover. However the question yet left unanswered is if these fluctuations are transferred to the brain, worthy of note is the fact that brain glutamate levels at any time exceed plasma levels. The blood brain barrier (BBB) largely prevents entry of exogenous glutamate into the brain (3). Until recently, the safety of glutamate has not been called into dispute considering it exists in nature and in the body in large quantities. Glutamate from added dietary monosodium glutamate was thought to be minimal compared to that gotten from ingestion of natural glutamate sources. Daily oral intake has been reported to vary from about 0.4 g/person in Europe to about to $3 \mathrm{~g} /$ person in Asia (4). However, recent documentations of its toxicities have necessitated caution in its use. Monosodium glutamate and its effects on the brain have been studied widely, Takasaki et al. in 1979 assessed quantitatively these effects and concluded that MSG was only neurotoxic when administered at very high doses and delivered as a bolus solution. High doses of MSG did not cause neurodegeneration when it was given as a food component although these doses were neurotoxic when administered as a gavage (5).

Glutamate is the brain s principal excitatory neurotransmitter and recently it is thought to be much more than a conventional neurotransmitter. In mature neurons, it is the predominant excitatory neurotransmitter; glutamate also influences the proliferation, migration, differentiation and survival of immature neurons (6). Glutamate and its receptors are essential in the normal functioning of the brain and spinal cord, although excessive activation by glutamate is thought to contribute to neuronal damage in many neurological disorders ranging from hypoxic-ischemic and traumatic brain injuries to chronic neurodegenerative diseases such as Alzheimer's disease, Parkinson's disease and Huntington's disease $(7,8)$. The effects of MSG and by extension glutamate on behavior have been studied usually with respect to many variables (e.g. age, time course of 
administration and neurobehavioral models and dose of MSG). Carter and Levesque (9) studying the effects of MSG on neurobehavior in rats reported a reduction in novelty induced behavior in the open field at 2 and $4 \mathrm{mg} / \mathrm{g}$, Onaolapo and Onaolapo also studied the effects of acute intraperitoneal injection of MSG at very low doses on behavior in the open field and concluded that acutely administered MSG retards novelty- induced behaviors in male mice (10). The results from our previous study necessitated a further assessment of the possible effects of MSG on spatial memory using the Y-maze and on a model of anxiety

\subsection{EQUIPMENTS AND APPARATUS}

\section{Materials And Method}

Electronic precision balance, plastic animal cages, sterile disposable syringes $(1,5$ and $10 \mathrm{ml})$ and needles, cotton wool, stop watch and Elevated Plus-maze, Y-maze.

\subsection{REAGENTS AND DRUGS}

Normal Saline, 99\% monosodium glutamate (Ajinomoto brand) was purchased from the market, weighed and dissolved in measured volume of isotonic saline solution to get desired concentrations. MSG at the varying doses $(0.5,1.0$ and $1.5 \mathrm{mg} / \mathrm{kg})(10)$ was administered orally using a cannula.

\subsection{ANIMALS}

Healthy adult Swiss albino mice purchased from the Empire Animal farms, Osogbo, Osun State, Nigeria with weights ranging between 20 to $25 \mathrm{~g}$ were used. The animals were housed in plastic cages measuring 16"x12"x10" (10 mice in each cage). All animals had free access to food and water ad libitum. They were maintained under standard laboratory conditions that is, a well aerated room with alternating light and dark cycles of $12 \mathrm{~h}$ each and at room temperature of $25^{\circ} \mathrm{C}$. The experimental protocol was approved by the Ladoke Akintola University Animal Ethics Committee. All rules applying to animal safety and care were observed.

\subsection{EXPERIMENTAL METHOD}

Forty animals were used for each of the experiments. The animals were randomly assigned into four groups A, B, C and D. Group A was the control and received normal saline. Groups B, C and D received MSG orally at $0.5,1.0$ and $1.5 \mathrm{mg} / \mathrm{kg}$ respectively for a period of 14 days; the animals were exposed to the elevated plus maze model and the Y-maze after the last dose of MSG.

\subsection{BEHAVIORAL TESTS}

The behavioral tests were conducted in a large quite room between the hours of 8 a.m. and 4 p.m. Anxiolytic or anxiogenic effects of MSG or vehicle were evaluated using the elevated plus maze while locomotor activity and spatial memory were assessed using the Y-maze. Behaviors were scored by the authors using a stop watch; all animals in one group were tested on the same day. All events were observed manually.

\section{Elevated Plus Maze}

The elevated plus maze is a plus shaped apparatus with four arms at right angles to each other as described by Handley and Mithani (11). The two open arms lie across from each other measuring $25 \times 5 \times 5 \mathrm{~cm}$ and perpendicular to two closed arms measuring $25 \times 5 \times 16 \mathrm{~cm}$ with a center platform $(5 \times 5 \times 0.5 \mathrm{~cm})$. The closed arms have a high wall $(16 \mathrm{~cm})$ to enclose the arms whereas the open arms have no side wall. Following administration of MSG or vehicle, mice were placed in the central platform facing the closed arm and their behavior recorded for $5 \mathrm{~min}$. based upon the early studies by Montgomery $(12,13)$. The criterion for arm visit was considered only when the animal decisively moved all its four limbs into an arm. The maze was cleaned with 5\% ethanol after each trial. The elevated plus maze relies upon rodents' proclivity toward dark, enclosed spaces (approach) and an unconditioned fear of heights/open spaces (avoidance) (13). The percentage of time spent in the arms was calculated as time in open arms or closed arm/total time x100, the number of entries into the arms was calculated using number of entries into open or closed arms/total number of entries $(14,15)$.

\section{Y-MAZE}

It is well known that spontaneous alternation is a measure of spatial working memory. The Y-maze can be used as a measure of short term memory, general locomotor activity and stereotypic behavior (16). Therefore, spontaneous alternation was assessed using a Y- maze composed of three equally spaced arms $\left(120^{\circ}\right.$, $41 \mathrm{~cm}$ long and $15 \mathrm{~cm}$ high). The floor of each arm is made of Perspex and is $5 \mathrm{~cm}$ wide. Each mouse was placed in one of the arm compartments and was allowed to move freely until its tail completely enters another arm. The sequence of arm entries is manually recorded, the arms being labelled A, B, or C. An alternation is defined as entry into all three arms consecutively, for instance if the animal makes the following arm entries; $\mathrm{ACB}, \mathrm{CA}, \mathrm{B}, \mathrm{C}, \mathrm{A}, \mathrm{CAB}, \mathrm{C}, \mathrm{A}$, in this example, the animal made 13 arm entries 8 of which are correct alternations. 
The number of maximum spontaneous alternations is then the total number of arms entered minus two, and the percentage alternation is calculated as $\{$ (actual alternations /maximum alternations) $\mathrm{x} 100\}$. For each animal the Y-maze testing was carried out for 5 minutes. The apparatus was cleaned with 5\% alcohol and allowed to dry between sessions.

\subsection{STATISTICAL ANALYSIS}

All behavioral data were analyzed using one way analysis of variance (ANOVA) followed by post hoc tests (Student Newman Keul's) carried out to determine the source of a significant effect. Results were expressed as Mean \pm S.E.M., $\mathrm{p}<0.05$ was taken as accepted level of significant difference from control.

\subsection{EFFECT OF MONOSODIUM GLUTAMATE ON PERCENTAGE TIME SPENT IN THE OPEN OR CLOSED ARMS}

Figure 1 shows the effect of MSG on the percentage time spent in the open and closed arms following 5 minutes of exploration in the elevated plus maze. There was a significant reduction in time spent in the open arm at all doses of MSG compared to control ( $F=47.31, p>0.05)$. There was also an increase in time spent in the closed arm with increasing doses of MSG compared to control, this differences were however only visual. Comparing percentage time spent in the open arm to the closed arm, the animals spent significantly more time in the closed arm than they did in the open arm at all doses of MSG.

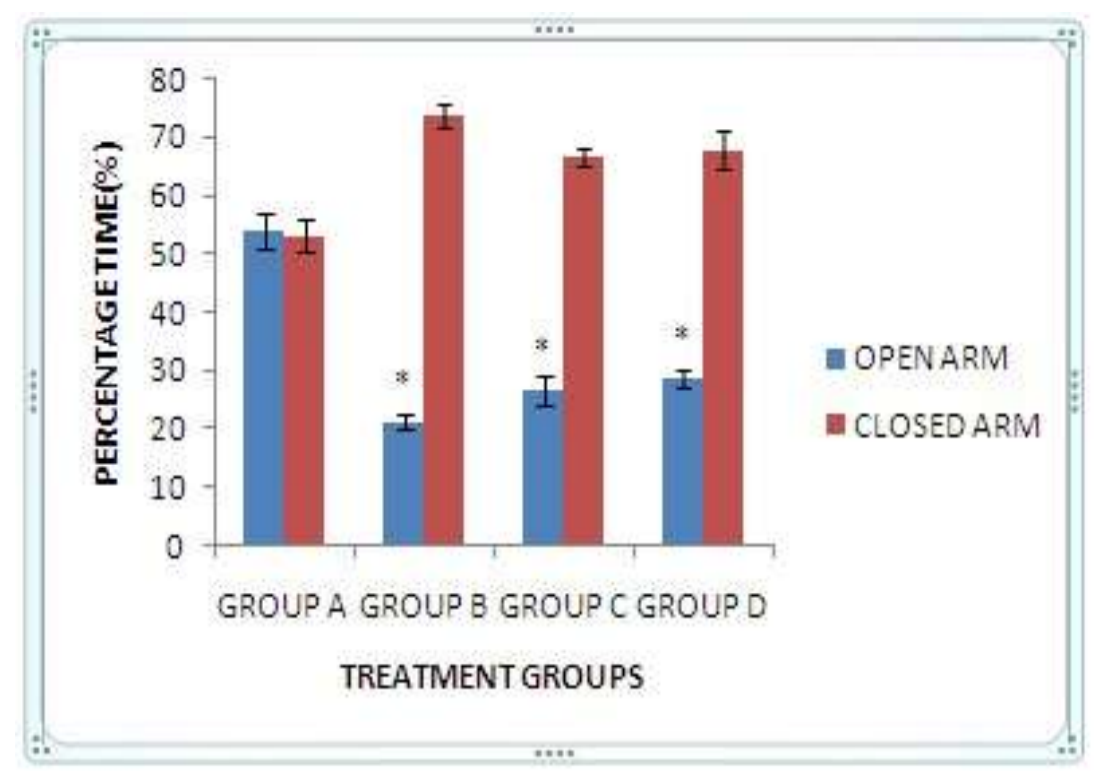

Figure 1: Effect of MSG $(0.5,1.0$ and $1.5 \mathrm{mg} / \mathrm{kg})$ on time spent in the open and closed arms during 5 minutes of elevated plus maze exploration. Each bar represents Mean \pm S.E.M, ${ }^{*} \mathrm{p} \leq 0.05$ compared to the control, $\mathrm{n}=10$. A is control, B, C and D received MSG at $0.5,1.0,1.5 \mathrm{mg} / \mathrm{kg}$ respectively.

\subsection{EFFECT OF MONOSODIUM GLUTAMATE ON NUMBER OF OPEN OR CLOSED ARM ENTRIES.}

Figure 2 shows the effects of MSG on the number of entries into the open and closed arms following 5 minutes of exploration in the elevated plus maze. There was a reduction in the number of entries into the open arm with increasing doses of MSG compared to control. At $1.5 \mathrm{mg} / \mathrm{kg}$ dose this difference was significant (F$3.38, \mathrm{p}=0.029)$. There was also an increase in the total number of closed arm entries made by the animals treated with MSG compared to control. The differences were however only visual. Comparing the number of entries into the closed arm to open arm entries revealed that at $1.5 \mathrm{mg} / \mathrm{kg}$, closed arm entry was significantly more than open arm entry. There were also increases in closed arm entries at the other doses but the difference seen was only visual. 


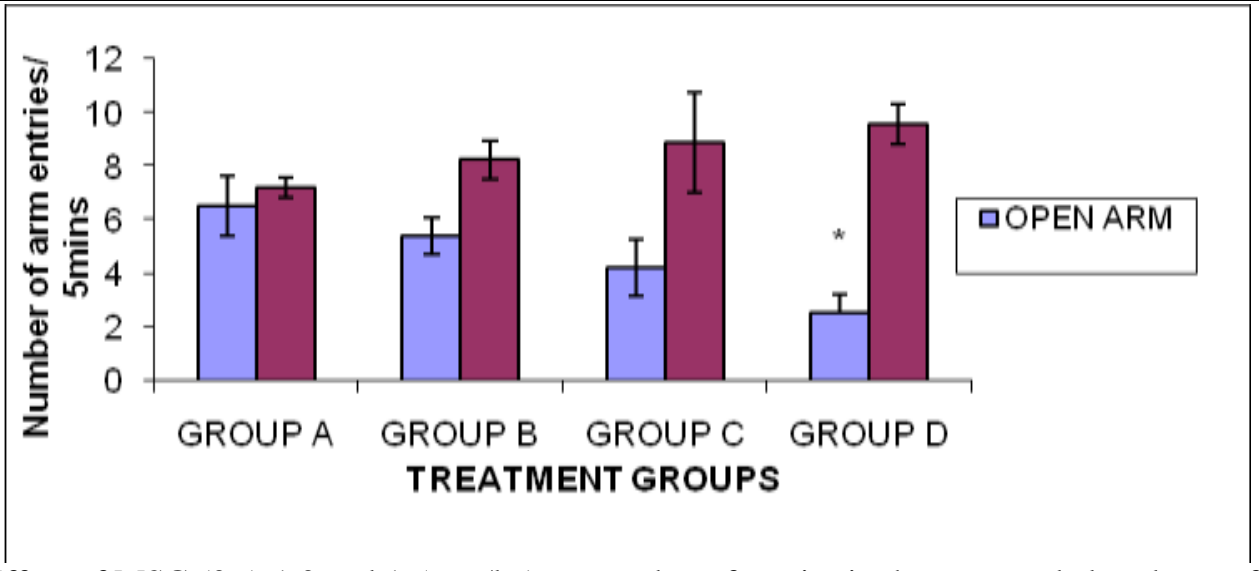

Figure 2: Effect of MSG $(0.5,1.0$ and $1.5 \mathrm{mg} / \mathrm{kg}$ ) on number of entries in the open and closed arms following 5 minutes of elevated plus maze exploration. Each bar represents Mean \pm S.E.M, ${ }^{*} p \leq 0.05$ compared to the control, $\mathrm{n}=10$. A is control, $\mathrm{B}, \mathrm{C}$ and $\mathrm{D}$ received $\mathrm{MSG}$ at $0.5,1.0,1.5 \mathrm{mg} / \mathrm{kg}$ respectively.

\subsection{EFFECT OF MONOSODIUM GLUTAMATE ON TOTAL NUMBER OF ARM ENTRIES}

Figure 3 shows effects of MSG on total arm number of arm entries entry following 5 minutes of exploration in the elevated plus maze. There was an increase in the number of arm entries with increasing doses of MSG compared to control. This difference was only visual.

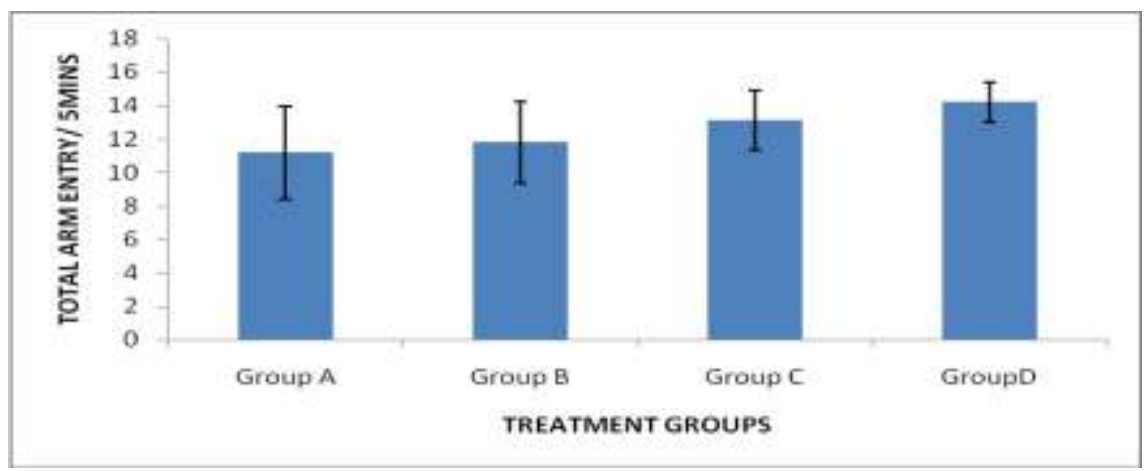

Figure 3: Effect of MSG $(0.5,1.0,1.5 \mathrm{mg} / \mathrm{kg})$ on total number of arm entries following 5 minutes of elevated plus maze exploration. Each bar represents Mean \pm S.E.M, $\mathrm{p} \leq 0.05$ compared to the control, $\mathrm{n}=10$. A control, $\mathrm{B}$, $\mathrm{C}$ and D received MSG at $0.5,1.0,1.5 \mathrm{mg} / \mathrm{kg}$ respectively.

\subsection{EFFECT OF MONOSODIUM GLUTAMATE ON Y- MAZE LOCOMOTOR ACTIVITY}

Figure 4 shows the effects of MSG on locomotor activity following 5mins of exposure in the $\mathrm{Y}$ maze. There was a slight increase in locomotor activity at $0.5 \mathrm{mg} / \mathrm{kg}$ compared to control, while at the other two doses a reduction in activity was seen. However, neither effect was statistically significant.

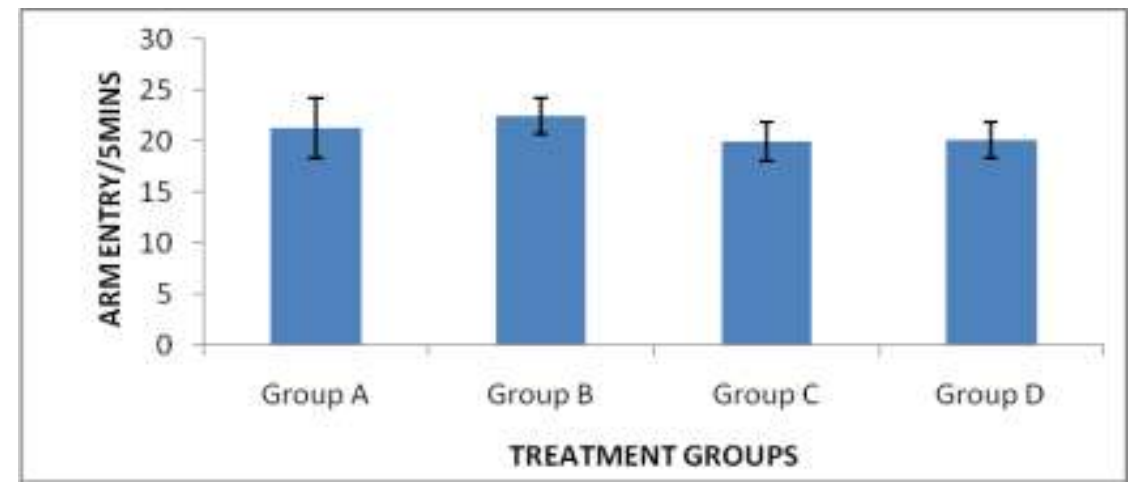


Figure 5: Effect of MSG $(0.5,1.0$ and $1.5 \mathrm{mg} / \mathrm{kg})$ on spatial memory following 5 minutes of exploration in the $\mathrm{Y}$ maze. Each bar represents Mean \pm S.E.M, * $\mathrm{p} \leq 0.05$ compared to the control, $\mathrm{n}=10, \mathrm{~A}$ is control, $\mathrm{B}, \mathrm{C}$ and $\mathrm{D}$ received MSG at $0.5,1.0,1.5 \mathrm{mg} / \mathrm{kg}$ respectively.

\subsection{EFFECTS OF MONOSODIUM GLUTAMATE ON Y - MAZE ON SPATIAL MEMORY}

Figure 5 shows the effects of MSG on spatial memory following 5mins of exposure in the Y maze. There was a dose dependent reduction in spatial memory at increasing doses of MSG compared to controls, although the difference was only visual

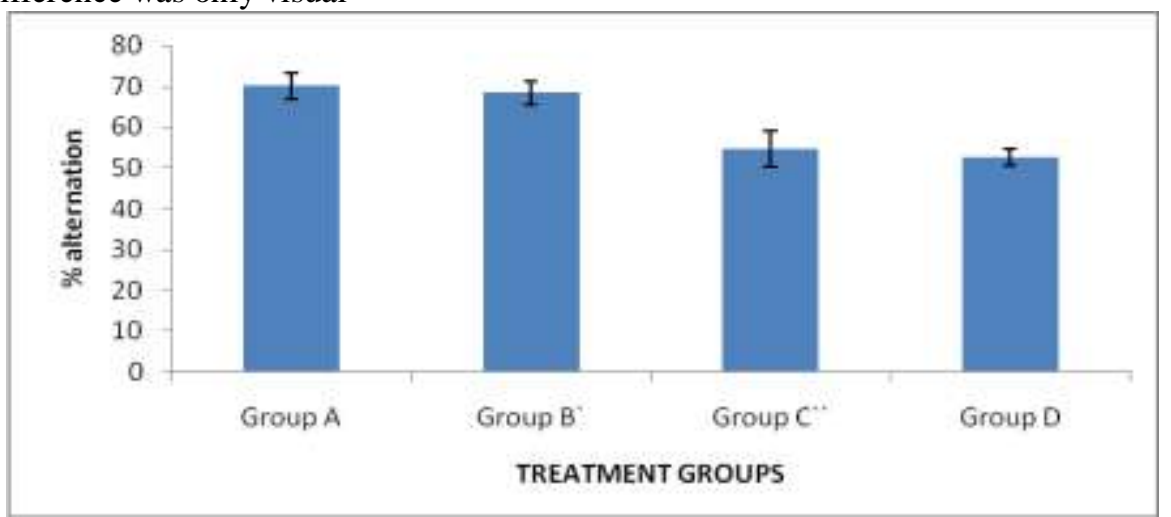

Figure 5: Effect of MSG $(0.5,1.0$ and $1.5 \mathrm{mg} / \mathrm{kg})$ on spatial memory following 5 minutes of exploration in the Y maze. Each bar represents Mean \pm S.E.M, * $\mathrm{p} \leq 0.05$ compared to the control, $\mathrm{n}=10, \mathrm{~A}$ is control, $\mathrm{B}, \mathrm{C}$ and $\mathrm{D}$ received MSG at $0.5,1.0,1.5 \mathrm{mg} / \mathrm{kg}$ respectively.

\section{DISCUSSION}

Glutamate within the brain and spinal cord has more functions than being a simple excitatory neurotransmitter, as it is important in the pathogenesis of learning and anxiety disorders $(17,18)$. Its interaction with glutamate receptors, more importantly NMDA receptors forms the basis for long-term potentiation and depression in memory processes, it is also implicated in anxiety disorders and studies have corroborated anxiety like response seen with MSG. This study set out to assess the possible anxiogenic or anxiolytic and memory enhancing or retarding effects of low dose MSG in mice. Studies have indicated that MSG treatment results in behavioral changes in mice that are reproducible $(19,10)$; results from this study supports such earlier reports. The data showed a reduction in number of entries into and time spent in the open arm at all doses of MSG studied. An anxiogenic drug e.g. (yohimbine, pentylenetetrazole, caffeine, amphetamine) in rodents significantly reduces the percentage of entries into, and time spent in the open arms (20). In an earlier study, aqueous solution of $2 \mathrm{mg} / \mathrm{g}$ body weight of MSG was administered and a substantial reduction in open arms exploration time in MSG treated rats during the EPM test was observed compared to control (21).

Untreated rodents avoid the open arms of the plus maze preferring the closed arms, whereas those treated with antianxiety drugs like benzodiazepines show far less open-arm avoidance than seen with controls (22). As it occurred in our study, when administration of a drug results in a significant increase in open arm avoidance compared to control, such a drug is said to be anxiogenic. Glutamate- GABA (gamma amino butyric acid) imbalance has been implicated in anxiety disorders and the response elicited following subchronic oral MSG could only mean that sustained administration of monosodium glutamate resulted in an increase in brain glutamate levels enough to alter the glutamate GABA balance.

Locomotor activity is another index that can be observed from the total number of arm entries, (23) or preferably the number of closed arm entries. However, there is a lot of ambiguity with respect to the 'pure' indicator of locomotor activity index of the EPM (24). Our study showed an increase in the number of total arm entries as well as an increase in the number of closed arm entries although neither one was significant. Some authors have described a reduction in locomotor activity with MSG (25); a view disputed by others (26).

An earlier study in our laboratory showed reduction in horizontal and vertical locomotor (rearing) activity in MSG treated mice at all doses during open field tests following acute intraperitoneal administration of MSG. This effect of MSG on locomotion was thought to be due to MSG's modulatory effects on hypothalamic brain regions, glutamate is also known to exert its actions by affecting the release of other neurotransmitters in this case probably monoamines and GABA (27). Injections of glutamate antagonists enhanced locomotion and this was abolished by dopamine (28) suggesting that glutamate retards locomotion by interaction with dopamine. If acute and subchronic administration of MSG resulted in two different responses locomotor-wise, then it is possible that an acute increase in brain glutamate levels is inhibitory by it actions on GABA (27) or other monoamines while sustained increases is excitatory by reason of its actions on dopamine or other monoamines, or both responses be due to an initial enhancing of dopamine followed by a negative feedback effect. 
Elevated Plus Maze And Y-Maze Behavioural Effects of Subchronic, Oral Low Dose Monosodium

Learning is a behavioral modification following an experience while memory involves the retention of the modification (29). The Y-maze spatial memory task also showed that MSG causes a reduction in spatial learning and memory and these was noticed at 1.0 and $1.5 \mathrm{mg} / \mathrm{kg}$ compared to control although this effect was only visual, this however corroborate recent studies that have sought to explore the relationship between MSG, memory and learning, and reported that MSG does lead to decreases in performance on spatial memory and learning tasks $(30,31,32,33)$. The mechanisms responsible for these effects seen with MSG are still being studied although the role of glutamate and its receptors in learning and memory has been well researched and the importance of glutamate receptors on memory formations is well established (34), assertions are that MSG interferes with stabilized glutamate synthesis in the hippocampus, resulting in impaired spatial memory and learning. Short-term memory impairment as well as physical debilitations were also thought to be responsible $(31,35)$. In some other studies, the interaction between glutamate and the cholinergic transmission have been researched and conclusions are that the inhibition of the cholinergic mechanism, brought on by MSG may be responsible for deficient learning and memory in mice $(19,36)$. Wong $(36)$, in the same study concluded that NMDA glutamate receptors had decreased efficiency, and the combined deficiencies in glutamate and cholinergic system could present a very convincing explanation for the disparity between MSG-treated mice and controls.

Deficits in behavior and performance in spatial memory and learning tasks in MSG treated mice could have a number of possible explanations. The underlying thread is that MSG one way or another impairs performance in memory and learning. Whether this impairment is a result of deficient NMDA glutamate receptors in the hippocampus, degenerative retinal function impairing vision, cholinergic deficiency leading to reduced acetylcholine synthesis, or a combination of parameters is the ultimate question. These studies have a common front that MSG significantly effects spatial memory and learning and from our study we can affirm that at doses considered safe there are deficits in memory albeit only visual, could it be that the platform for a final onslaught of dementia in adulthood is laid daily. More studies need to be done to clarify its safety profile in humans.

\section{CONCLUSION}

This study concluded that subchronic low dose monosodium glutamate is significantly anxiogenic with a slight memory retardant effect. While monosodium glutamate is still being consumed as a constituent of many food additives or taste enhancers, even at low doses, it has the ability to alter brain behavior.

\section{References}

[1] Yoshida Y. Umami Taste and Traditional Seasonings, Food Reviews international, Vol.14, 1998, pp 213-246.

[2] Oldendorf W.H. Brain uptake of radiolabeled amino acids, amines, and hexoses after arterial injection. Am J Physiol; Vol.221, 1971, pp 1629-1639

[3] Mallick H.N. Understanding safety of glutamate in food and brain, Indian J Physiol Pharmacol., Vol. 51, No.3, 2007, pp 216-234

[4] Glacometti T. Free and bound glutamate in natural products. In: Glutamic acid: Advances in Biochemistry (Filer LJ. Garattini S. Kare MR. Reynolds WA. Wurtman RJ. Eds.); 1979, pp. 25-34. Raven Press, New York

[5] Takasaki Y, Matsuzawa Y, Iwata S, O’hara Y, Yonetani S, Ichimura M. Toxicological studies of monosodium L-glutamate in rodents; relationship between routes of administration and nneurotoxicity. In: Glutamic Acid: Advances in Biochemistry (Filer LJ. Garattini S. Kare MR.Reynolds WA. Wurtman RJ. Eds.),1979, pp. 255-275. Raven Press, New York.

[6] Schlett K. Glutamate as a modulator of embryonic and adult neurogenesis. Curr Top Med Chem, Vol.6, 2006, pp 949-960

[7] Platt SR. The role of glutamate in central nervous system health and disease-a review. Vet J; Vol.173, 2007, pp 278-286.

[8] Pelligrini-Giampetro, D. E., Gorter, J. A., Bennett, M.V.L. \& Zukin, R. S. The GluR2 (GluR-B) hypothesis: Ca21-permeable AMPA receptors in neurological disorders. Trends Neurosci. Vol. 20, 1997, pp 464-470

[9] Carter LT, Levesque L. Monosodium glutamate-induced changes of aggression and open-field activity in rats. Neurobehav. Toxicol. Vol.1, No. 4, 1979, pp 247-251.

[10] Onaolapo OJ and Onaolapo AY. Acute low dose monosodium glutamate retards novelty Induced behaviours in male Swiss albino mice Journal of Neuroscience and Behavioral Health, Vol. 3 No. 4, pp 51 - 56 ISSN 2141-2286

[11] Handley, S.L. \& Mithani, S. Effects of adrenoreceptor agonists and antagonists in a maze-exploration model of 'fear'-motivated behaviour. Naunyn-Schmeideberg's Arch. Pharmacol. Vol. 327 1984, pp 1

[12] Montgomery, K.C. The relation between fear induced by novel stimulation and exploratory behavior. J. Comp. Physiol. Psychol. Vol.48,1958, pp 254-260

[13] Pellow S and File SE. Anxiolytic and anxiogenic drug effects on exploratory activity in an elevated plus-maze: a novel test of anxiety in the rat. Pharmacol Biochem Behav, Vol. 24, No.3, 1997, pp 525-9. "http://dx.doi.org/10.1016\%2

[14] Barnett, SA.The Rat; A Study in Behaviour, Univ. Chicago Press, Chicago

[15] Hogg S. A review of the validity and variability of the elevated plus-maze as an animal model of anxiety. Pharmacol Biochem Behav, Vol.54, 1996, pp 21-30.http://dx.doi.org/10.1016\%2

[16] Kokkinidis L, Walsh MD, Lahue R, Anisman H. Tolerance to damphetamine: Behavioral specificity. Life Sci., Vol.18, 1976, pp 913-917

[17] Stanton P.K. Long term depression, Long term potentiation, and the sliding threshold for long-term synaptic plasticity. Hippocampus, Vol.6, 1996, pp35-42.

[18] Meldrum B.S. Glutamate as a neurotransmitter in the brain: review of physiology and pathology. J Nutr. Vol. 130, No. 4S, 2000, pp 1007S-1015S

[19] Hlinák Z, Gandalovicová D and Krejcí I. Behavioral deficits in adult rats treated neonatally with glutamate. Neurotoxicol. Teratol., Vol.,27, No.3, 2005, pp 465-473 http://dx.doi.org/10.1016\%2 
[20] Pellow S., Chopin P., File S.E., Briley M. Validation of open: closed arm entries in an elevated plus-maze as a measure of anxiety in the rat. J. Neurosci. Methods, Vol. 14, 1985, pp 149-167

[21] Narayanan, S.N., R.S. Kumar, J. Paval and S. Nayak. Effect of ascorbic acid on monosodium glutamate induced neurobehavioral changes in periadolescent rats. Bratisel Lek Listy, Vol. 111, No. 5, 2010, pp247-252.

[22] Treit Dallas, Menard Janet, and Royan Cary,(1993) Anxiogenic stimuli in the elevated plus-maze, Pharmacology Biochemistry and Behavior Volume 44, Issue 2, pp 463-469

[23] Lister R.G. The use of a plus-maze to measure anxiety in the mouse. Psychopharmacology (Berl.) Vol. 92 1987, pp 180-185

[24] Bourin Michel, Petit-Demoulie`re Benoit, Dhonnchadha Brid Nic and Hasco"et Martine. Animal models of anxiety in mice Fundamental \& Clinical Pharmacology Vol.21, 2007, pp 567-574, doi: 10.1111/j.1472-8206.2007.00526.x

[25] Dawson Jr. R, Annau Z. A behavioral assessment of arcuate nucleus damage after a single injection of monosodium glutamate, Neurobehav. Toxicol. Teratol., Vol.5, 1983, pp399-406

[26] Grimm EV, Frieder B. Differential vulnerability of male and female rats to the timing of various perinatal insults. Int. J. Neurosci, Vol.27, 1987, pp 155-164

[27] Cortese BM, Phan LK . The Role of Glutamate in Anxiety and Related Disorders CNS. Spectr. Vol. 10, No.10, 2005, pp 820-830.

[28] Dalia A, Uretsky NJ, Wallace LJ. Induction of locomotor activity by the glutamate antagonist DNQX injected into the ventral tegmental area. Brain Res., Vol. 728, 1996, pp 209-214.

[29] Riedel Gernot, Platt Bettina, Micheau Jacques. Glutamate receptor function in learning and memory Behavioural Brain Research Vol. 140, No.1-2, 2003, pp 1-4 http://dx.doi.org/10.1016/S0166-4328(02)00272-3

[30] Collison KS, Makhoul NJ, Inglis A, Al-Johi M, Zaidi MZ, Maqbool Z, Saleh SM, Bakheet R, Mondreal R, Al-Rabiah R, Shoukri M, Milgram NW, Al-Mohanna FA. Dietary trans-fat combined with monosodium glutamate induces dyslipidemia and impairs spatial memory.Physiol Behav. Vol. 99, No. 3, 2010, pp 334-42.

[31] Olvera-Cortes E, Lopez-Vazquez MA, Beas-Zarate C, Gonzalez-Burgos I. Neonatal exposure to MSG disrupts place learning ability in adult rats.Pharmacology Biochemistry and Behavior. Vol.82, No.2, 2005, pp 247-251.

[32] Park CH, Choi SH, Piaoa Y, Kim S, Lee Y, Kim, Jeong S, Rah J, Seo J, Lee J, Chang K, Jung Y, Suh Y: (2000); Glutamate and Aspartate impair memory retention and damage hypothalamic neurons in adult mice, Toxicol. Lett., Vol.115, No. 2, 2000, pp 117125 http://dx.doi.org/10.1016\%2.

[33] Kubo T, Kohira R, Okano T, Ishikawa K. Neonatal glutamate can destroy the hippocampal CA1 structure and impair discrimination learning in rats. Brain Res, Vol.616, No. 1-2, 1993, pp311-4

[34] Morris RG, Anderson E, Lynch GS, Baudry M. Selective impairment of learning and blockade of long-term potentiation by an Nmethyl-D-aspartate receptor antagonist, AP5. Nature. Vol., 27, No. 319, 1986, pp 774-6.

[35] Frieder B and Grimm VE. Prenatal monosodium glutamate (MSG) treatment given through the mother's diet causes behavioral deficits in rat offspring. Intern J Neurosci. Vol.23, 1984, pp 117-126.

[36] Wong PT, Neo H, Teo WL, Feng H, Xue YD, Loke WH, Deficits in Water Escape Performance and Alterations in Hippocampal Cholinergic Mechanisms Associated with Neonatal Monosodium Glutamate Treatment in Mice. Pharmacology Biochemistry and Behavior Vol 57, No.1-2, 1997, pp 383-388. 